\title{
Resistance training improves quality of life in people with HIV: a randomized clinical trial
}

\section{Treinamento resistido melhora qualidade de vida em pessoas com HIV: ensaio clínico randomizado}

\begin{abstract}
The study aimed to evaluate the effect of periodized resistance training on the quality of life of people infected with HIV. Thirty HI$V$-infected people, sedentary and receiving antiretroviral therapy, were randomly divided into two groups. The resistance training group $(R T)$ participated in a 12-week periodized exercise program while the control group (CON) was asked to maintain daily babits. Before and after the twelve weeks, all volunteers answered a quality of life questionnaire (Patient-Reported Outcomes Quality of Life-HIV) in the Portuguese language version, containing eight domains: 1) physical health and symptoms (PHS); 2) body change (BC); 3) social relationships (SR); 4) intimate relationships (IR); 5) stigma (ST); 6) emotional distress (ED); 7) bealth concerns (HC); and 8) treatment impact (TI). A mixed-design analysis of variance for repeated measures was used to analyze the effects of time, treatment and interaction, having significant value when $p$ $<0.05$. Interactions were found for the following domains: $P H S(p$ $<0.0001), B D(p<0.0001), S R(p<0.0001), I R(p<0.002), S T(p$ $<0.0001), E D(p<0.0001), H C(P<0.0001)$ and TI $(p<0.0001)$. $R T$ improves quality of life in $H I V$-infected individuals and points to the need for its implementation in health care services targeted at this population.
\end{abstract}

\section{Keywords}

Human Immunodeficiency Virus; Acquired Immunodeficiency Syndrome; Quality of Life; Exercise.

\section{Resumo}

Avaliar o efeito do exercício resistido periodizado na qualidade de vida de pessoas infectadas pelo HIV. Trinta pessoas infectadas pelo HIV, sedentários e em uso de terapia antirretroviral foram randomicamente alocados em dois grupos. $\mathrm{O}$ grupo treinamento resistido (TR) participou de um programa de 12 semanas de exercício físico periodizado enquanto o grupo controle $(\mathrm{CON})$ foi orientado a manter os hábitos diários. Antes e após as doze semanas, todos os voluntários responderam um questionário de qualidade de vida (Patient-Reported Outcomes Quality of Life HIV Instrument) na versão para língua portuguesa, contendo oito domínios: 1) saúde física e sintomas (SFS); 2) mudanças corporais (MC); 3) relacionamento social (RS); 4) relacionamento íntimo (RI); 5) estigma (ES); 6) angústia emocional (AE); 7) preocupações com a saúde (PS) e; 8) impacto do tratamento (IT). A análise de variância de design misto de medidas repetidas foi empregada para análise dos efeitos do tempo, tratamento e interação, tendo valor significativo quando $p<0,05$. Foram encontradas interações para os domínios SFS ( $\mathrm{p}<0,0001) ; \mathrm{MC}(\mathrm{p}<0,0001)$; RS ( $<<0,0001)$; RI ( $=0,002 ; \operatorname{ES}(p<.0001) ; \operatorname{AE}(p<0,0001) ;$ PS $(p<0,0001)$ e IT $(p$ $<0,0001)$. TR melhorou todos domínios da qualidade de vida em pessoas infectadas pelo HIV e sinaliza para necessidade de sua implementação nos serviços de atenção à saúde dessa população.

\section{Palavras-chave}

Vírus da imunodeficiência humana; Síndrome da Imunodeficiência Adquirida; Qualidade de vida; Exercício físico.

\section{Introduction}

Since the beginning of detection tests, infection caused by the Human Immunodeficiency Virus (HIV) and the Acquired Immunodeficiency Syndrome (AIDS) have become international public health problems,

1 Universidade Federal do Triângulo Mineiro - Programa de Pós-Graduação em Educação Física - Uberaba/MG, Brasil and there has been growing concern about the infected individuals' life and quality of life. However, the development of drugs to control the replication of the virus in the bloodstream in the mid-1990s has significantly increased survival time and has changed the epidemiological profile of HIV infection ${ }^{1,2}$.

Adherence to antiretroviral therapy (ART) has positive effects on clinical results: it controls the ad- 
vance of the disease, reduces viral replication, increases the count of $\mathrm{CD} 4^{+} \mathrm{lym}$ phocytes and reduces patients' mortality rate ${ }^{3}$. However, ART causes undesirable effects that include chronic fatigue, nausea, vomits, diarrhea, nephropathy, cardiovascular diseases, hepatotoxicity and persistent immunosuppression ${ }^{2,4,5}$. These symptoms produce a ripple effect that begins with discontinuity of medication use, increases the possibility of development of opportunistic infections, and culminates in an increase in HIV resistance. These events contribute to deteriorate the health and quality of life of the infected person ${ }^{6}$.

The individual's perception of their position in life in the context of the culture and value systems in which they live and in relation to their goals, expectations, standards and concerns defines the term "quality of life"7. It is known that HIV infection directly affects the emotional, social and sexual life of infected individuals ${ }^{8,9}$. Thus, it is important to measure quality of life, mainly in clinical practice, to complement routine tests like viral load, $\mathrm{CD}^{+}$cell count and history of opportunistic diseases ${ }^{10}$.

Although more than three decades have elapsed since the emergence of HIV, studies on the quality of life of infected people remain controversial. The first studies were carried out before the emergence of ART and included physical variables like generalized pain and fatigue. These studies found deterioration in the quality of life of patients for whom more time had passed since HIV diagnosis ${ }^{11}$. Life expectancy of HIV-infected people has been increasing and intervention proposals to improve quality of life should be concerned about factors that influence effectiveness, increasing adherence and reducing costs ${ }^{12}$.

Therefore, physical exercise has emerged as a simple, low-cost tool with a positive impact on the quality of life of diverse population groups. One of these groups is HIV-infected individuals, mainly because it reduces the side effects caused by $\mathrm{ART}^{13-16}$. Roubenoff and Wilson ${ }^{17}$ have reported that HIV-infected people enrolled in a resistance training (RT) program presented an improvement in self-reported physical function. In addition, the study carried out by Gomes et al. ${ }^{18}$ evaluated the effect of programs combining strength, flexibility and aerobic exercises and observed an improvement in HIV-infected people's perception of satisfaction. Other RT approaches need to be tested in order to amplify the possibilities of application to treatment of HIV-infected people. Thus, the present study aimed to evaluate the effect of RT periodized in a non-linear way on the quality of life of HIV-infected people.

\section{Methods}

\section{Sample}

Sample size (34 individuals) was calculated by the software $G^{*}$ power with selection of the statistical test ANOVA for repeated measures (2 groups $\mathrm{x} 2$ times) and interaction, moderate size effect $(F=0.25)$, an $80 \%$ power and a $5 \%$ significance level.

Initially, 50 patients infected with HIV were identified in the sector of Infectious and Parasitic Diseases of Hospital das Clinicas of Universidade Federal do Triângulo Mineiro (state of Minas Gerais, Southeastern Brazil), and all of them were invited to participate in the study. The following inclusion criteria were adopted: having a positive diagnosis for HIV infection; having been receiving ART for at least one year; being between 18 and 60 years of age; not having practiced systematized physical exercise over the past six months; not having had opportunistic diseases over 
the past five years; not having heart problems, neuropathy, hepatopathy nor nephropathy. Fifteen patients did not meet the inclusion criteria and five decided not to participate after they were informed of the study's development (Figure 1). The 30 patients who accepted to participate were randomly allocated to two groups: resistance training $(\mathrm{RT}, \mathrm{n}=15)$ and control group $(\mathrm{CON}, \mathrm{n}=15)$.

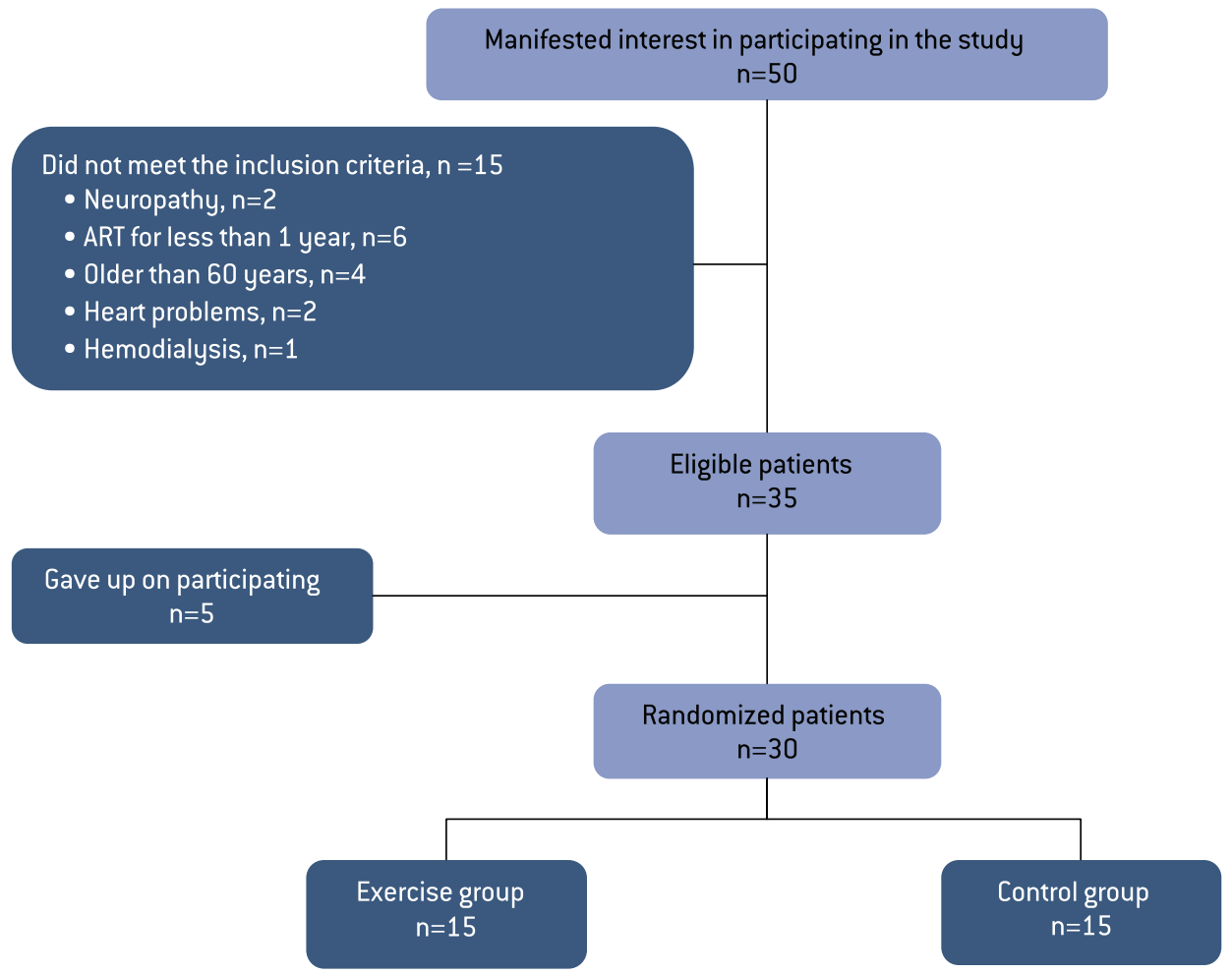

FIGURE 1 - Flowchart of the study's participants.

\section{Procedures}

Initially, the participants were interviewed to collect demographic data and disease status. Afterwards, they were submitted to a physical assessment. In addition, before and after the 12-week program, the participants answered a questionnaire about quality of life.

\section{Demographic aspects and disease status}

The participants answered a questionnaire developed by the researchers themselves to collect data referring to sex, age, race and complete level of schooling (elementary, high school or higher education). Time since diagnosis and the period of time during which the participant has been receiving ART were obtained from the medical records of each participant.

\section{Anthropometric measures}

Body mass (kg) and height (meters) were measured by means of a mechanical scale with a stadiometer (Filizola ${ }^{\circledR}$, Campo Grande, state of Mato Grosso do Sul, Brazil. Maximum capacity: $150 \mathrm{~kg}$; sensitivity: 100 grams; precision: $0.1 \mathrm{~cm}$ ). Body Mass Index (BMI) was obtained by means of the Quetelet index $\left(\mathrm{BMI}=\right.$ body mass $(\mathrm{kg}) /$ height $\left.^{2}(\mathrm{~m})\right)$.

\section{Quality of Life}

To verify the participants' quality of life, we used the Patient-Reported Outcomes 
Quality of Life-HIV Instrument (PROQOL-HIV), Portuguese version ${ }^{19}$. This instrument is composed of 43 questions divided into eight domains, namely: 1) physical health and symptoms (PHS) (9 questions); 2) body change (BC) (4 questions); 3 ) social relationships (SR) (2 questions); 4) intimate relationships (IR) (3 questions); 5) stigma (ST) (2 questions); 6) emotional distress (ED) (4 questions); 7) health concerns (HC) (4 questions); and 8) treatment impact (TI) (10 questions). Moreover, the global health domain (1 question) and the domain referring to religious and financial conditions (4 questions) do not suffer score effect.

Patients were questioned about the degree in which they had experienced each domain over the past 12 weeks. Each question had a five-point Likert scale in which: 0 - "never"; 1 = "rarely"; 2 = "sometimes"; 3 = "frequently"; and 4 = "always". To determine the final score, the instrument provides specific equations to each domain ${ }^{19}$.

The questionnaire was administered in a hospital environment, with the presence of the evaluator and the participant only. This procedure was adopted to minimize the embarrassment bias and the occurrence of influences on the answers. Only one evaluator was responsible for the interviews. All the questions and options of answers were read in detail, and the first answer given by the patient was marked.

\section{Resistance exercise program}

The RT group was submitted to twelve weeks of physical exercise performed three times per week on nonconsecutive days and supervised by a Physical Education professional. The exercises and periodization are presented in Table 1.

TABLE 1 - Protocol of periodized non-linear resistance exercise performed by HIV-infected patients during 12 weeks.

\begin{tabular}{llll}
\hline Exercise/Day of the Week & Monday* $^{*}$ & Wednesday** & Friday*** $^{* *}$ \\
\hline Squat & $3 \times 4-6 \mathrm{MR}$ & $3 \times 15-20 \mathrm{MR}$ & $3 \times 8-12 \mathrm{MR}$ \\
\hline Bench Press & $3 \times 4-6 \mathrm{MR}$ & $3 \times 15-20 \mathrm{MR}$ & $3 \times 8-12 \mathrm{MR}$ \\
\hline Flexor & $3 \times 4-6 \mathrm{MR}$ & $3 \times 15-20 \mathrm{MR}$ & $3 \times 8-12 \mathrm{MR}$ \\
\hline Frontal Pull & $3 \times 4-6 \mathrm{MR}$ & $3 \times 15-20 \mathrm{MR}$ & $3 \times 8-12 \mathrm{MR}$ \\
\hline Calf & $3 \times 4-6 \mathrm{MR}$ & $3 \times 15-20 \mathrm{MR}$ & $3 \times 8-12 \mathrm{MR}$ \\
\hline Shoulder Development & $3 \times 4-6 \mathrm{MR}$ & $3 \times 15-20 \mathrm{MR}$ & $3 \times 8-12 \mathrm{MR}$ \\
\hline
\end{tabular}

* Recovery Interval (RI) between series = 3'; ** RI of 45"; ${ }^{* *} \mathrm{RI}$ of 1'30"; MR: maximum repetitions.

\section{Ethical procedures}

All the participants in this study were informed about the objectives and risks. Participation was voluntary and the participants read and signed a consent document. The study's methods and procedures were approved by the Ethics Committee for Research with Human Beings (protocol no. 994.745/2015) and by the Brazilian Register of Clinical Trials (protocol RBR-4rnq3v).

\section{Statistical analyses}

Data normality was verified by the Shapiro-Wilk test. The Mauchly test verified sphericity violation (F) for repeated measures and, when this value was violated, the Greenhouse-Geisser correction was used. A mixed-design analysis of variance (ANOVA) for repeated measures was used to analyze the effects of time, treatment and interaction. Cohen's $d$ coefficient was used to estimate the magnitude of the effect $\left(\eta^{2}\right)$ of the intervention, interpreted as small $\left(\eta^{2}=0.2\right)$, medium $\left(\eta^{2}=0.5\right)$, or large $\left(\eta^{2}=0.8\right)^{20}$. Statistical significance was established in $5 \%$ for all the analyses. 
The software Statistical Package for the Social Sciences (SPSS) 20.0, Portuguese version, was utilized for the analyses.

\section{Results}

The desired sample size to guarantee the magnitude of moderate effect and the test's power $(80 \%)$ to reveal interaction effects was 34 patients. However, after applying the inclusion criteria and after providing information about the development of the study, 30 patients were randomized into two groups. This fact reduced the test's power to $75 \%$.

Table 2 shows the demographic profile and disease status of the HIV-infected patients. The total sample was composed of a majority of men $(56.6 \%)$ of white ethnicity (50\%), whose level of schooling was equal to or lower than elementary school (63.3\%). There was no difference between groups regarding age $(\mathrm{p}=0.833)$, ART time $(\mathrm{p}=0.253), \mathrm{CD} 4^{+}$cell count $(\mathrm{p}=0.756)$ and viral load $(\mathrm{p}=0.625)$.

TABLE 2 - Demographic profile and disease status of HIV-infected patients.

\begin{tabular}{|c|c|c|c|}
\hline & $\begin{array}{c}\text { NLRT } \\
(n=15)\end{array}$ & $\begin{array}{c}\text { CON } \\
(n=15)\end{array}$ & $p$-value \\
\hline $\operatorname{Sex}(M / F)(n)$ & $8 / 7$ & $9 / 6$ & \\
\hline Age (mean \pm sd) & $41.5 \pm 11.4$ & $40.7 \pm 8.8$ & 0.833 \\
\hline BMI (mean \pm sd) & $22.9 \pm 4$ & $22.9 \pm 3.4$ & \\
\hline \multicolumn{4}{|l|}{ Race } \\
\hline White (n) & 8 & 7 & \\
\hline Mixed ethnicity (white and black) (n) & 3 & 5 & \\
\hline Black (n) & 4 & 3 & \\
\hline \multicolumn{4}{|l|}{ Level of Schooling } \\
\hline Elementary School or below (n) & 8 & 11 & \\
\hline High School (n) & 4 & 2 & \\
\hline Higher Education (n) & 3 & 2 & \\
\hline Infection Time, years (mean \pm sd) & $10.3 \pm 6.1$ & $13.3 \pm 6.1$ & 0.336 \\
\hline ART Time, years (mean \pm sd) & $7.3 \pm 3.5$ & $8.6 \pm 4.2$ & 0.253 \\
\hline $\mathrm{CD}^{+}$Count, cells/ $\mu \mathrm{L}$ (mean $\pm \mathrm{sd}$ ) & $576.2 \pm 164$ & $579.8 \pm 200$ & 0.756 \\
\hline Viral Load, copies/mL (mean \pm sd) & $57.2 \pm 102$ & $56.2 \pm 100$ & 0.625 \\
\hline
\end{tabular}

NLRT: Nonlinear Resistance Training; CON: control; M: male; F: female; BMI: body mass index; sd = standard deviation; $\mathrm{n}=$ number of subjects.

Table 3 presents the quality of life domains with the respective values before and after 12 weeks. It is observed that there was interaction for PHS $\left[\mathrm{F}_{(1,28)}=\right.$ $\left.125.845, \mathrm{p}<0.0001 ; \eta^{2}=0.818\right] ; \mathrm{BD}\left[\mathrm{F}_{(1,28)}=114.116 ; \mathrm{p}<0.0001 ; \eta^{2}=0.803\right] ; \mathrm{SR}$ $\left[\mathrm{F}_{(1,28)}=14.365 ; \mathrm{p}<0.0001 ; \eta^{2}=0.339\right] ; \mathrm{IR}\left[\mathrm{F}_{(1,28)}=12.081, \mathrm{p}=0.002 ; \eta^{2}=0.301\right] ; \mathrm{ST}$ $\left[\mathrm{F}_{(1,28)}=15.758 ; \mathrm{p}<0.0001 ; \eta^{2}=0.360\right] ; \mathrm{ED}\left[\mathrm{F}_{(1,28)}=19.750 ; \mathrm{p}<0.0001 ; \eta^{2}=0.414\right] ;$ $\mathrm{HC}\left[\mathrm{F}_{(1,28)}=24.967 ; \mathrm{p}<0.0001 ; \eta^{2}=0.471\right] ;$ TI $\left[\mathrm{F}_{(1,28)}=30.288 ; \mathrm{p}<0.0001 ; \eta^{2}=0.520\right]$.

\section{Discussion}

This study verified the effect of 12 weeks of periodized resistance training on the quality of life of HIV-infected patients. Participation in the physical exercise program improved all the quality of life domains, mainly "physical health and symptoms" and "body change". The effect's magnitude was considered large according to Cohen's methodology ${ }^{20}$.

Nowadays, HIV infection represents living with a chronic disease, which opens 
TABLE 3 - Score of the domains of the quality of life questionnaire (PROQOL) in HIV-infected patients before and after 12 weeks of intervention.

\begin{tabular}{|c|c|c|c|c|c|c|c|}
\hline \multirow{2}{*}{ Domains } & \multicolumn{2}{|c|}{$\operatorname{NLRT}(n=15)$} & \multicolumn{2}{|c|}{$\operatorname{CON}(n=15)$} & \multicolumn{3}{|c|}{ ANOVA (p) } \\
\hline & BEFORE & AFTER & BEFORE & AFTER & Time & Group & Interaction \\
\hline PHS & $50.3 \pm 13.3$ & $86.8 \pm 6.1^{*}$ & $55.1 \pm 9.6$ & $50.1 \pm 12.9$ & 0.001 & 0.001 & 0.001 \\
\hline $\mathrm{BD}$ & $47.5 \pm 13.5$ & $87.0 \pm 9.2^{*}$ & $55.4 \pm 20.8$ & $52.1 \pm 18.6$ & 0.365 & 0.006 & 0.001 \\
\hline$S R$ & $73.3 \pm 29.2$ & $95.1 \pm 7.9^{*}$ & $75.0 \pm 22.1$ & $70.0 \pm 18.1$ & 0.128 & 0.254 & 0.001 \\
\hline $\mathbb{R}$ & $61.1 \pm 27.7$ & $82.7 \pm 15.2^{*}$ & $61.1 \pm 27.9$ & $58.0 \pm 29.2$ & 0.273 & 0.053 & 0.002 \\
\hline ST & $41.6 \pm 26.5$ & $55.6 \pm 15.5^{*}$ & $41.6 \pm 27.8$ & $42.3 \pm 19.9$ & 0.288 & 0.288 & 0.001 \\
\hline ED & $44.1 \pm 22.7$ & $80.4 \pm 11.2^{*}$ & $45.8 \pm 21.7$ & $44.1 \pm 20.6$ & 0.001 & 0.012 & 0.001 \\
\hline $\mathrm{HC}$ & $31.2 \pm 17.3$ & $61.2 \pm 19.5^{*}$ & $31.6 \pm 16.2$ & $29.1 \pm 18.1$ & 0.006 & 0.002 & 0.001 \\
\hline $\mathrm{TI}$ & $74.8 \pm 11.1$ & $85.6 \pm 7.8^{*}$ & $75 \pm 9.16$ & $71.1 \pm 11.4$ & 0.580 & 0.005 & 0.001 \\
\hline
\end{tabular}

NLRT: Nonlinear resistance training; PHS: physical health and symptoms; BD: body change; 3) SR: social relationships; IR: intimate relationships; ST: stigma; ED: emotional distress; HC: health concerns; TI: treatment impact; ${ }^{*}$ significant difference.

space for non-pharmacological interventions like physical exercise ${ }^{21}$. Physical exercise enables to maintain functionality and improves quality of life $\mathrm{fe}^{22,23}$, as our study has demonstrated. Thus, maintenance of physical and functional aptitude has become one of the priority objectives in the treatment of patients living with HIV/AIDS, mainly those with a diagnosis of pronounced loss of muscle mass ${ }^{24}$. Generally speaking, it is understood that physical-functional aptitude helps to improve quality of life perception ${ }^{25}$ and the findings presented in this study corroborate this line of reasoning.

Furthermore, HIV-infected people present changes in their self-concept of body image ${ }^{26}$. In the majority of cases, this perception is related to lipodystrophy syndrome, characterized by an increase in central adiposity and lipoatrophy in the peripheral region of the body ${ }^{4}$. The results of the present study are in accordance with what was discussed above, as there was an effect that was considered large $\left(\eta^{2}=0.803\right)$ for the domain "body change" after the intervention with periodized resistance training. Resistance training is known to be effective for muscle mass increase and body adiposity reduction, which contributes to improve quality of life in this domain.

Beyond alterations in physiological factors, regular physical exercise favors mental health. Recent evidence suggests that physically active people, independently of the type of training, present improvements in their wellbeing, as well as reductions in depression symptoms ${ }^{27}$. These data corroborate the findings of this study, as the studied domains were potentially better in the RT group when compared to the CON group. In order to understand the mechanism through which exercise can improve psychological functions and, consequently, quality of life, LaPerriere ${ }^{28}$ et al. have proposed an immuno-psycho-physiological model. In this model, regular physical exercise contributes to improve emotional state, increasing the liberation of endogenous opioids and reducing activity in the hypothalamic-pituitary- adrenocortical system. Thus, physical training would have the potential for modulating psycho-physiological sequelae of chronic diseases, including HIV.

Finally, it is important to highlight that quality of life is a valuable aspect during the therapeutic process of the HIV-infected patient. Although it is a subjective aspect, it must be taken into account, as it can be used as a parameter for decision-making referring to treatments and approval of new therapeutic regimes ${ }^{29}$. In addition, we highlight that the participants in the present study have low level of schooling 
and low purchasing power, which strengthens the need to restructure health care models that are based exclusively on the pharmacological context. It is necessary to expand the teams that provide health care for HIV-infected patients, with the inclusion of Physical Education professionals, and to amplify and strengthen practice scenarios that include patients and professionals in the context of physical exercise.

In spite of some methodological limitations, mainly the non-control of the participants' nutrition routine and a small sample size, this study suggests that regular practice of physical exercise directly influences the quality of life of HIV -infected people.

\section{References}

1. Lange JM, Ananworanich J. The discovery and development of antiretroviral agents. Antiviral therapy. 2014;19 Suppl 3:5-14.

2. Hartmann M. The side effects of antiretroviral therapy. Der Hautarzt; Zeitschrift fur Dermatologie, Venerologie, und verwandte Gebiete. 2006;57(11):969-74.

3. Chiou PY, Kuo BI, Lee MB, Chen YM, Chuang P, Lin LC. A programme of symptom management for improving quality of life and drug adherence in AIDS/HIV patients. Journal of advanced nursing. 2006;55(2):169-79.

4. Barbaro G. Metabolic and cardiovascular complications of highly active antiretroviral therapy for HIV infection. Current HIV research. 2006;4(1):79-85.

5. Havlir DV, Currier JS. Complications of HIV disease and antiretroviral therapy. Topics in HIV medicine : a publication of the International AIDS Society, USA. 2006;14(1):27-35.

6. Ruiz-Perez I, Olry de Labry-Lima A, Prada-Pardal JL, Rodriguez-Bano J, CaussePrados M, Lopez-Ruz MA, et al. Impact of demographic and psychosocial factors on adherence to antiretroviral treatment. Enfermedades infecciosas y microbiologia clinica. 2006;24(6):373-8.

7. Canavarro MC, Serra AV, Simoes MR, Rijo D, Pereira M, Gameiro S, et al. Development and psychometric properties of the World Health Organization Quality of Life Assessment Instrument (WHOQOL-100) in Portugal. International journal of behavioral medicine. 2009;16(2):116-24.

8. Bajunirwe F, Tisch DJ, King CH, Arts EJ, Debanne SM, Sethi AK. Quality of life and social support among patients receiving antiretroviral therapy in Western Uganda. AIDS care. 2009;21(3):271-9.

9. Mrus JM, Williams PL, Tsevat J, Cohn SE, Wu AW. Gender differences in health-related quality of life in patients with HIV/AIDS. Quality of life research : an international journal of quality of life aspects of treatment, care and rehabilitation. 2005;14(2):479-91.

10. Casado A. Measurement of quality of life of HIV individuals: Perspectives \& future directions. The Indian journal of medical research. 2005;122(4):282-4.

11. Breitbart W, Passik S, McDonald MV, Rosenfeld B, Smith M, Kaim M, et al. Patient-related barriers to pain management in ambulatory AIDS patients. Pain. 1998;76(1-2):9-16.

12. Wren A. How best to approach endocrine evaluation in patients with HIV in the era of combined antiretroviral therapy? Clinical endocrinology. 2013;79(3):310-3.

13. Malita FM, Karelis AD, Toma E, Rabasa-Lhoret R. Effects of different types of exercise on body composition and fat distribution in HIV-infected patients: a brief review. Canadian journal of applied physiology = Revue canadienne de physiologie appliquee. 2005;30(2):233-45.

14. Mendes EL, Ribeiro Andaki AC, Brito CJ, Cordova C, Natali AJ, Santos Amorim PR, et al. Beneficial effects of physical activity in an HIV-infected woman with lipodystrophy: a case report. Journal of medical case reports. 2011;5:430.

15. Troseid M, Ditlevsen S, Hvid T, Gerstoft J, Grondahl T, Pedersen BK, et al. Reduced trunk fat and triglycerides after strength training are associated with reduced LPS levels in HIVinfected individuals. Journal of acquired immune deficiency syndromes. 2014;66(2):e52-4.

16. Yarasheski KE, Tebas P, Stanerson B, Claxton S, Marin D, Bae K, et al. Resistance exercise training reduces hypertriglyceridemia in HIV-infected men treated with antiviral therapy. Journal of applied physiology. 2001;90(1):133-8. 
17. RoubenoffR, Wilson IB. Effect of resistance training on self-reported physical functioning in HIV infection. Medicine and science in sports and exercise. 2001;33(11):1811-7.

18. Gomes RD, Borges JP, Lima DB, Farinatti PT. Effects of physical exercise in the perception of life satisfaction and immunological function in HIV-infected patients: Non-randomized clinical trial. Revista brasileira de fisioterapia. 2010;14(5):390-5.

19. Duracinsky M, Herrmann S, Berzins B, Armstrong AR, Kohli R, Le Coeur S, et al. The development of PROQOL-HIV: an international instrument to assess the health-related quality of life of persons living with HIV/AIDS. Journal of acquired immune deficiency syndromes. 2012;59(5):498-505.

20. Cohen J. Statistical Power Analysis for the Behavioral Sciences, 2nd edn. Hillsdale, NJ: Laurence Erlbaum Associates1988.

21. Scevola D, Di Matteo A, Lanzarini P, Uberti F, Scevola S, Bernini V, et al. Effect of exercise and strength training on cardiovascular status in HIV-infected patients receiving highly active antiretroviral therapy. Aids. 2003;17 Suppl 1:S123-9.

22. Yahiaoui A, Smith BA, Voss JG. Effect of exercise on cardiac and metabolic outcomes in people living with HIV. Annual review of nursing research. 2013;31:277-96.

23. Rueda S, Raboud J, Mustard C, Bayoumi A, Lavis JN, Rourke SB. Employment status is associated with both physical and mental health quality of life in people living with HIV. AIDS care. 2011;23(4):435-43.

24. Raso V, Shephard RJ, Casseb J, Duarte AJdS, Silva PRS, Greve JMDA. Association between muscle strength and the cardiopulmonary status of individuals living with HIV/AIDS. Clinics. 2013;68:359-64.

25. Roubenoff R. Acquired immunodeficiency syndrome wasting, functional performance, and quality of life. The American journal of managed care. 2000;6(9):1003-16.

26. Santos CP, Felipe YX, Braga PE, Ramos D, Lima RO, Segurado AC. Self-perception of body changes in persons living with HIV/AIDS: prevalence and associated factors. Aids. 2005;19 Suppl 4:S14-21.

27. Takacs J. Regular physical activity and mental health. The role of exercise in prevention and intervention of depressive disorders. Psychiatria Hungarica : A Magyar Pszichiatriai Tarsasag tudomanyos folyoirata. 2014;29(4):386-97.

28. LaPerriere A, Ironson G, Antoni MH, Schneiderman N, Klimas N, Fletcher MA. Exercise and psychoneuroimmunology. Medicine and science in sports and exercise. 1994;26(2):182-90.

29. Ruiz-Perez I, Olry de Labry-Lima A, Lopez-Ruz MA, del Arco-Jimenez A, RodriguezBano J, Causse-Prados M, et al. Clinical status, adherence to HAART and quality of life in HIV-infected patients receiving antiretroviral treatment. Enfermedades infecciosas y microbiologia clinica. 2005;23(10):581-5.

CORRESPONDING

AUTHOR

HUGO RIBEIRO ZANETT

hugo.zanetti@hotmail.com
Universidade Federal do Triângulo Mineiro

Programa de Pós-Graduação em Educação Física

- Avenida Tutunas, no 490 Bairro Tutunas - CEP:

38061-500 - Uberaba/MG, Brasil

Tel.: (34) 3318-5067
RECEIVED 10/12/2015

REVIEWD 23/12/2015

APPROVED $\quad 23 / 12 / 2015$ 